\title{
UCHL1 S18Y variant is a risk factor for Parkinson's disease in Japan
}

\author{
Yoshihiro Miyake ${ }^{1 *}$, Keiko Tanaka', Wakaba Fukushima ${ }^{2}$, Chikako Kiyohara ${ }^{3}$, Satoshi Sasaki ${ }^{4}$, Yoshio Tsuboi $^{5}$, \\ Tatsuo Yamada ${ }^{5}$, Tomoko Oeda ${ }^{6}$, Hiroyuki Shimada7, Nobutoshi Kawamura ${ }^{8}$, Nobutaka Sakae ${ }^{8}$, \\ Hidenao Fukuyama ${ }^{9}$, Yoshio Hirota ${ }^{2}$, Masaki Nagai ${ }^{10}$ and the Fukuoka Kinki Parkinson's Disease Study Group ${ }^{11}$
}

\begin{abstract}
Background: A recent meta-analysis on the UCHL1 S18Y variant and Parkinson's disease (PD) showed a significant inverse association between the Y allele and PD; the individual studies included in that meta-analysis, however, have produced conflicting results. We examined the relationship between UCHL1 S18Y single nucleotide polymorphism (SNP) and sporadic PD in Japan.

Methods: Included were 229 cases within 6 years of onset of PD, defined according to the UK PD Society Brain Bank clinical diagnostic criteria. Controls were 357 inpatients and outpatients without neurodegenerative disease. Adjustment was made for sex, age, region of residence, smoking, and caffeine intake.

Results: Compared with subjects with the CC or CA genotype of UCHL1 S18Y SNP, those with the AA genotype had a significantly increased risk of sporadic PD: the adjusted OR was 1.57 (95 \% Cl: $1.06-2.31)$. Compared with subjects with the CC or CA genotype of UCHL1 S18Y and the CC or CT genotype of SNCA SNP rs356220, those with the AA genotype of UCHL1 S18Y and the TT genotype of SNP rs356220 had a significantly increased risk of sporadic PD; the interaction, however, was not significant. Our previous investigation found significant inverse relationships between smoking and caffeine intake and PD in this population. There were no significant interactions between UCHL1 S18Y and smoking or caffeine intake affecting sporadic PD.

Conclusions: This study reveals that the UCHL1 S18Y variant is a risk factor for sporadic PD. We could not find evidence for interactions affecting sporadic PD between UCHL1 S18Y and SNCA SNP rs356220, smoking, or caffeine intake.
\end{abstract}

\section{Background}

The ubiquitin proteasome system regulates the degradation of key regulatory proteins as well as misfolded and damaged proteins [1]. Ubiquitin carboxy-terminal hydrolase L1 (UCHL1) is a 223-amino acid protein that belongs to the family of deubiquitinating enzymes known as UCHL1 -5 . UCHL1 is selectively and abundantly expressed in neurons, constituting 1-2\% of total soluble brain protein [2]. It is known to generate free monomeric ubiquitin from ubiquitin proproteins [3]. UCHL1 activity has been shown to be required for normal synaptic function: pharmacological suppression of UCHL1 significantly reduces monomeric ubiquitin levels

\footnotetext{
* Correspondence: miyake-y@fukuoka-u.ac.jp

${ }^{1}$ Department of Preventive Medicine and Public Health, Faculty of Medicine, Fukuoka University, Fukuoka, Japan

Full list of author information is available at the end of the article
}

and causes alterations in synaptic protein distribution and spine morphology [4].

The UCHL1 gene is located on chromosome $4 \mathrm{p} 14$. The S18Y variant arises due to a cytosine-to-adenine transversion at codon 18 of exon 3 (rs5030732). Ragland et al. [5] conducted a meta-analysis of published casecontrol studies concerning the UCHL1 S18Y variant and Parkinson's disease (PD), which indicated a significant inverse association between the $\mathrm{Y}$ allele and $\mathrm{PD}$ under a recessive model using data from studies in populations of Asian ancestry and a similar significant inverse relationship under a dominant model using data from studies in populations of European ancestry. It is worth noting, however, that the 15 studies included in this meta-analysis [6-20] and another five recent studies that were not included in the meta-analysis [21-25] have produced conflicting results. 
Here, we examined the relationship between UCHL1 S18Y single nucleotide polymorphism (SNP) and the risk of sporadic PD using data from a multicenter hospitalbased case-control study in Japan. Because UCHL1 and $\alpha$-synuclein proteins co-localized on the halo of Lewy bodies in a patient with sporadic PD [26], we also investigated the possibility of an interaction between $U C H L 1$ S18Y SNP and SNCA SNP rs356220. Moreover, possible interactions between UCHL1 S18Y and smoking or caffeine intake were assessed.

\section{Methods}

\section{Study population}

\section{Recruitment of cases}

Patients with PD were recruited at 3 university hospitals and 1 national hospital in Fukuoka Prefecture, a metropolitan area of Kyushu Island in southern Japan, and in 3 university hospitals, 3 national hospitals and 1 municipal hospital in Osaka, Kyoto, and Wakayama Prefectures, which are part of the Kinki region, located in the midwestern part of the mainland. Eligible patients were within 6 years of the onset of PD and had been diagnosed by one of the collaborating neurologists according to the United Kingdom PD Society Brain Bank clinical diagnostic criteria [27]. The neurologists in charge asked eligible PD patients to take part in our case-control study. Of 298 eligible PD patients identified during the period between 1 April 2006 and 31 March 2008, 250 agreed to participate in the study (response rate: $84 \%$ ).

\section{Recruitment of control subjects}

During the same period, control subjects without a previous diagnosis of neurodegenerative disease were recruited from departments other than the neurology departments (orthopedic surgery, ophthalmology, otorhinolaryngology, plastic surgery, and oral surgery) at 3 of the 11 collaborating hospitals: 1 university hospital in Fukuoka Prefecture and 1 university hospital and 1 national hospital in the Kinki region. Control subjects were not, individually or in larger groups, matched to cases. Potential control subjects were asked by an attending doctor or by one of our research nurses to participate in our case-control study when they were seen as outpatients or hospitalized at any of these 3 hospitals. Altogether, 372 of the potential control subjects participated in our study whereas 156 refused (response rate: $70 \%)$.

\section{The present study population}

Of the 250 cases and 372 controls who participated in our study, 240 cases and 371 controls gave informed consent to genotyping. Excluded were 11 cases and 12 controls with a family history of PD, 1 control with missing data on smoking, and 1 control with missing data on caffeine intake, leaving data on 229 cases and 357 control subjects available for analysis. The ethics committees of the 11 collaborating hospitals (Fukuoka University; Utano National Hospital; Osaka City University; Kyushu University; Wakayama Medical University; Kyoto University; Kurume University; Minami-Kyoto National Hospital; Toneyama National Hospital; Kyoto City Hospital; and National Omuta Hospital) approved our case-control study. Written informed consent was obtained from all subjects.

\section{Questionnaires}

Participants filled out a set of 2 self-administered questionnaires and mailed these materials to the data management center or handed them to research nurses. Our research technicians completed missing answers and/or illogical data by telephone or in-person interview.

Dietary habits during the preceding month were assessed using a self-administered, semi-quantitative, comprehensive diet history questionnaire. Reported intake levels of coffee, black tea, and Japanese and Chinese teas, including green tea and oolong tea, were used to estimate caffeine intake. Energy-adjusted intake was calculated according to the density method. A second questionnaire elicited information on sex, age, smoking habits, and family history of PD. A history of smoking was defined as having smoked at least once per day for at least one year.

\section{DNA extraction and genotyping}

The attending physicians or our research nurses collected buccal specimens with BuccalAmp swabs (Epicenter BioTechnologies, Madison, WI, USA). Genomic DNA was extracted using a BuccalAmp DNA extraction kit (Epicenter BioTechnologies). Genotyping was performed using a TaqMan SNP Genotyping Assay on a StepOnePlus machine, according to the manufacturer's instructions (Applied Biosystems, Foster City, CA, USA).

\section{Statistical analysis}

We tested agreement with Hardy-Weinberg equilibrium among the control subjects using the chi-square test. Logistic regression analysis was applied to estimate crude odds ratios (ORs) and $95 \%$ confidence intervals (CIs) of sporadic PD in relation to UCHL1 S18Y SNP. Multiple logistic regression analysis was used to adjust for sex, age, region of residence, smoking, and caffeine intake. SNCA SNP rs356220, but not SNPs rs356229, rs356219, rs7684318, or rs2736990 under a recessive model [28], smoking [29], and caffeine intake [30] were significantly associated with the risk of PD in this population. We examined multiplicative and additive interactions between UCHL1 S18Y and SNCA SNP rs356220, smoking, or caffeine intake with regard to the risk of 
sporadic PD. Multiplicative interaction was estimated by introducing a multiplicative term into a multiple logistic regression model. Three measures for the additive interaction were calculated using the Excel sheet provided by Andersson et al. [31]: 1) relative excess risk due to interaction (RERI), 2) attributable proportion due to interaction (AP), and 3) synergy index (S). RERI is the excess risk due to an interaction relative to the risk without exposure. AP refers to the attributable proportion of disease among individuals exposed to both factors that is due to the factors' interaction. $\mathrm{S}$ is the excess risk from both exposures when there is an additive interaction, relative to the risk from both exposures without an interaction. $\mathrm{RERI}=0, \mathrm{AP}=0$, or $\mathrm{S}=1$ means no interaction or strict additivity; RERI $>0, \mathrm{AP}>0$, or $\mathrm{S}>1$ means positive interaction or more than additivity; $\mathrm{RERI}<0, \mathrm{AP}<0$, or $\mathrm{S}<1$ means negative interaction or less than additivity [32]. If any of the null values (0 in RERI and AP or 1 in S) falls outside the $95 \%$ CI of its respective measurement, then the additive interaction is considered statistically significant. All statistical analyses were performed using STATA/SE software version 12.0 (StataCorp, College Station, TX, USA).

\section{Results}

Compared with control subjects, cases were more likely to be older, to report never having smoked, and to report a low intake of caffeine (Table 1). There were no differences between cases and controls with regard to sex or region of residence.

There was no significant deviation from the HardyWeinberg equilibrium in the control subjects $(P=0.67)$.

Under a recessive model, compared with subjects with the CC or CA genotype of UCHL1 S18Y SNP, those with

Table 1 Characteristics of the study population

\begin{tabular}{|c|c|c|c|}
\hline \multirow[b]{2}{*}{ Variable } & \multicolumn{2}{|c|}{$n(\%)$ or mean (SD) } & \multirow[b]{2}{*}{$P$-value } \\
\hline & $\begin{array}{l}\text { Cases } \\
(N=229)\end{array}$ & $\begin{array}{l}\text { Controls } \\
(N=357)\end{array}$ & \\
\hline $\operatorname{Sex}(\%)$ & & & 0.90 \\
\hline Male & $88(38.4)$ & $139(38.9)$ & \\
\hline Female & $141(61.6)$ & $218(61.1)$ & \\
\hline Age, years & $68.4(8.7)$ & $66.6(8.5)$ & 0.02 \\
\hline Onset age, years & $65.7(8.8)$ & & \\
\hline Region of residence (\%) & & & 0.28 \\
\hline Fukuoka & $86(37.6)$ & $150(42.0)$ & \\
\hline Kinki & $143(62.5)$ & $207(58.0)$ & \\
\hline Ever smoked (\%) & & & 0.001 \\
\hline No & $167(72.9)$ & $212(59.4)$ & \\
\hline Yes & $62(27.1)$ & $145(40.6)$ & \\
\hline Caffeine intake, mg/4184 kJ & $149.3(110.8)$ & $194.0(139.2)$ & $<0.0001$ \\
\hline
\end{tabular}

the AA genotype had a significantly increased risk of sporadic PD after adjustment for sex, age, region of residence, smoking, and caffeine intake: the adjusted OR was 1.57 (95\% CI: 1.06 - 2.31) (Table 2). No such significant association was found under the co-dominant, additive, or dominant model. The frequency of the $\mathrm{A}$ allele was $52.0 \%$ in cases and $47.5 \%$ in controls; thus the allelic distribution was not significantly different between cases and controls $(P=0.13)$.

Based on the recessive model, compared with subjects with the CC or CT genotype of SNCA SNP rs356220, the TT genotype was significantly related to an increased risk of sporadic PD after adjustment for confounders: the adjusted OR was 1.47 (95\% CI: $1.03-2.10)$. Using subjects with the CC or CA genotype of UCHL1 S18Y SNP and the CC or CT genotype of SNCA SNP rs356220 as a reference group, those with the AA genotype of UCHL1 S18Y SNP and the TT genotype of SNCA SNP rs356220 had a significantly increased risk of sporadic PD; however, neither multiplicative nor additive interaction was statistically significant (Table 3 ).

Compared with ever having smoked, never having smoked was significantly related to an increased risk of sporadic PD after adjustment for sex, age, region of residence, and caffeine intake: the adjusted OR was 2.63 (95\% CI: 1.64-4.22). Compared with subjects with the CC or CA genotype of UCHL1 S18Y SNP who had ever smoked, those with the AA genotype who had never smoked had a 4.08-fold increased risk of sporadic PD; nevertheless, neither multiplicative nor additive interaction was significant (Table 4).

When caffeine intake was categorized into two groups, with the cut-off point defined as the median intake among control subjects, intake of less than $161.7 \mathrm{mg} / 4184 \mathrm{~kJ} /$ day was significantly associated with an increased risk of sporadic PD: the adjusted OR was 1.70 (95 \% CI: $1.20-2.41$ ). There was no significant multiplicative or additive interaction between UCHL1 S18Y SNP and caffeine intake (Table 5).

\section{Discussion}

To our knowledge, this is the first study to find a significant positive association between the UCHL1 S18Y variant and the risk of sporadic PD. Our results are at variance with those from the previously cited metaanalysis, which demonstrated a significant inverse association between the Y allele and PD [5]. The PDGene meta-analysis in the website (www.pdgene.org) demonstrated that the Y allele of UCHL1 S18Y SNP was significantly inversely related to PD using data from a total of 26 case-control samples; however, such a significant association was not observed using data from 12 case-control Asian samples [33]. Zhang et al. [6] showed that the frequency of the $\mathrm{Y}$ allele of UCHL1 
Table 2 Association of UCHL1 S18Y polymorphism with sporadic Parkinson's disease in a Japanese population

\begin{tabular}{|c|c|c|c|c|c|}
\hline \multirow[b]{2}{*}{ Model } & \multirow[b]{2}{*}{ Genotype } & \multicolumn{2}{|c|}{$n(\%)$} & \multirow[b]{2}{*}{ Crude OR (95 \% Cl) } & \multirow[b]{2}{*}{ Adjusted OR (95\% Cl) } \\
\hline & & Cases $(N=229)$ & Controls $(N=357)$ & & \\
\hline \multirow[t]{3}{*}{ Co-dominant } & CC & $61(26.6)$ & $96(26.9)$ & 1.00 & 1.00 \\
\hline & CA & $98(42.8)$ & $183(51.3)$ & $0.84(0.56-1.26)$ & $0.85(0.56-1.30)$ \\
\hline & AA & 70 (30.6) & $78(21.9)$ & $1.41(0.90-2.23)$ & $1.41(0.88-2.27)$ \\
\hline Additive & & & & $1.19(0.94-1.50)$ & $1.19(0.94-1.51)$ \\
\hline Dominant & & & & $1.01(0.70-1.47)$ & $1.02(0.69-1.51)$ \\
\hline Recessive & & & & $1.57(1.08-2.30)$ & $1.57(1.06-2.31)$ \\
\hline
\end{tabular}

*Adjusted for sex, age, region of residence, smoking, and caffeine intake.

S18Y SNP was significantly higher among control subjects than among PD patients in a Japanese population (crude $\mathrm{OR}=0.73$ [95 \% CI: $0.53-0.99]$ ), whereas, under a recessive model, the AA genotype was nonsignificantly positively associated with the risk of sporadic PD in a Caucasian population (crude $\mathrm{OR}=4.76$ [95 \% CI: $0.52-226.8$ ]); furthermore, the frequency of the AA genotype was much lower among Caucasians than among Japanese. A case-control study of Australians found a non-significant positive association between the AA genotype of UCHL1 S18Y SNP and PD under a recessive model (crude $\mathrm{OR}=3.14$ [95 \% CI: $0.76-18.32]$ ) [13]. The current results are in partial agreement with these results from Caucasian populations. With regard to the other case-control studies of Japanese, one study showed a significant inverse association between the AA genotype of UCHL1 S18Y SNP and PD [7], while such a significant association was not found in two other studies [9,25] (Table 6). The frequency of the AA genotype of UCHL1 S18Y SNP was lower among our control subjects than among control subjects in all of the previous studies of Japanese $[6,7,9,25]$. The inconsistency of our findings with those of other studies may be at least partly explained by differences in the genetic backgrounds of the populations examined, definitions of $\mathrm{PD}$, and statistical power. In a genome-wide association study of Japanese, there was no relationship between UCHL1 S18Y SNP and $\mathrm{PD}$ at a genome-wide significance level; however, about $64 \%$ of control subjects were those registered in BioBank Japan as subjects with diseases other than a neurological disease, and the mean age of the control subjects was 49.9 [34].

Andersson et al. [35] have shown that the S18Y form of UCHL1 is minimally perturbed compared to the wild type. Although the primary effect of the mutation is to slightly reduce stability, the structure is barely perturbed, as shown by fluorescence, far-UV CD, and NMR measurements: they have found no evidence that would suggest that S18Y may behave in such a way as to contribute to a decreased risk of PD [35]. We are unable to explain why we found a significant positive association between the UCHL1 S18Y variant and the risk of sporadic PD.

Co-localization of UCHL1 and $\alpha$-synuclein proteins in nigral Lewy bodies has been shown in human sporadic PD brain, suggesting a possible physical and/or functional interaction between the two proteins [26]. In

Table 3 Interaction between UCHL1 S18Y and SNCA rs356220 polymorphisms affecting sporadic Parkinson's disease in a Japanese population

\begin{tabular}{|c|c|c|c|c|}
\hline \multirow[b]{3}{*}{ Genotype } & \multicolumn{4}{|c|}{ SNCA rs356220 } \\
\hline & \multicolumn{2}{|c|}{$\mathrm{CC}+\mathrm{CT}$} & \multicolumn{2}{|c|}{ TT } \\
\hline & No. cases/controls & Adjusted OR $(95 \% \mathrm{Cl}) *$ & No. cases/controls & Adjusted OR $(95 \% \mathrm{Cl})^{*}$ \\
\hline $\mathrm{CC}+\mathrm{CA}$ & $92 / 182$ & 1.00 & $67 / 97$ & $1.44(0.94-2.19)$ \\
\hline AA & $37 / 48$ & $1.51(0.91-2.53)$ & $33 / 29$ & $2.31(1.29-4.14)$ \\
\hline \multicolumn{5}{|c|}{$P$ for multiplicative interaction $=0.91$} \\
\hline \multicolumn{5}{|c|}{ Measures of additive interaction ${ }^{\dagger}$} \\
\hline \multicolumn{5}{|c|}{ Relative excess risk due to interaction $(\mathrm{RERI})=0.34(95 \% \mathrm{Cl}$ : $-1.14-1.81)$} \\
\hline \multicolumn{5}{|c|}{ Attributable proportion due to interaction (AP) $=0.15(95 \% \mathrm{Cl}$ : $-0.44-0.73)$} \\
\hline Synergy i & 1.35 (95 \% Cl: $0.37-4$ & & & \\
\hline
\end{tabular}

*Adjusted for sex, age, region of residence, smoking, and caffeine intake.

${ }^{+}$Statistically significant when the $95 \% \mathrm{Cl}$ of RERI $>0$, the $95 \% \mathrm{Cl}$ of $\mathrm{AP}>0$, or the $95 \% \mathrm{Cl}$ of $\mathrm{S}>1$, indicating additive interaction. 
Table 4 Interaction between UCHL1 S18Y polymorphism and smoking status affecting sporadic Parkinson's disease in a Japanese population

\begin{tabular}{|c|c|c|c|c|}
\hline \multirow[b]{3}{*}{ Genotype } & \multicolumn{4}{|c|}{ Ever smoked } \\
\hline & \multicolumn{2}{|c|}{ Yes } & \multicolumn{2}{|c|}{ No } \\
\hline & No. cases/controls & Adjusted OR $(95 \% \mathrm{Cl})^{*}$ & No. cases/controls & Adjusted OR $(95 \% \mathrm{Cl})^{*}$ \\
\hline $\mathrm{CC}+\mathrm{CA}$ & $42 / 113$ & 1.00 & $117 / 166$ & $2.73(1.62-4.61)$ \\
\hline AA & $20 / 32$ & $1.72(0.87-3.38)$ & $50 / 46$ & $4.08(2.18-7.63)$ \\
\hline \multicolumn{5}{|c|}{$P$ for multiplicative interaction $=0.74$} \\
\hline \multicolumn{5}{|c|}{ Measures of additive interaction ${ }^{\dagger}$} \\
\hline \multicolumn{5}{|c|}{ Relative excess risk due to interaction (RERI) $=0.63$ (95\% Cl: $-1.48-2.75)$} \\
\hline \multicolumn{5}{|c|}{ Attributable proportion due to interaction (AP) $=0.16(95 \% \mathrm{Cl}:-0.31-0.62)$} \\
\hline \multicolumn{5}{|c|}{ Synergy index (S) = 1.26 (95 \% Cl: $0.59-2.68)$} \\
\hline
\end{tabular}

*Adjusted for sex, age, region of residence, and caffeine intake.

${ }^{+}$Statistically significant when the $95 \% \mathrm{Cl}$ of RERI $>0$, the $95 \% \mathrm{Cl}$ of $\mathrm{AP}>0$, or the $95 \% \mathrm{Cl}$ of $\mathrm{S}>1$, indicating additive interaction.

the current study, however, no significant interaction was found between UCHL1 S18Y and SNCA SNP rs356220 with respect to the risk of sporadic PD. With regard to gene-environment interactions, there were no significant interactions between UCHL1 S18Y and smoking or caffeine intake affecting the risk of sporadic PD; however, subjects with the AA genotype who had never smoked had a 4.08-fold increased risk of sporadic PD. A study of US individuals observed that UCHL1 and UCHL1 at the protein level were up-regulated in smokers compared with nonsmokers [36]. A case-control study using data from the NeuroGenetics Research Consortium found no significant interactions between UCHL1 S18Y and smoking or coffee intake with respect to the risk of PD [37].

Several limitations of our study warrant mention. First, data on family history of PD were self-reported; accordingly, it is assumed that some proportions of sporadic PD may be misclassified. Second, data on smoking and caffeine intake were also self-reported. Third, the current study size was rather small for a valid genetic association study. Although a significant positive relationship between UCHL1 S18Y SNP and sporadic PD was observed, the insignificant additive interactions under study might be attributable to insufficient statistical power. Fourth, correction for multiple testing was not performed in the present study because this is a hypothesis testing study. Fifth, although adjustment was made for some confounders, residual confounding effects could not be ruled out.

\section{Conclusions}

The results of the current Japanese case-control study reveal that the AA genotype of UCHL1 S18Y is significantly associated with an increased risk of sporadic PD under a recessive model. Nevertheless, we could not find evidence for interactions between UCHL1 S18Y and SNCA SNP rs356220, smoking, or caffeine intake with regard to the risk of sporadic $\mathrm{PD}$. We acknowledge that our findings must be confirmed by further case-control

Table 5 Interaction between UCHL1 S18Y polymorphism and caffeine intake affecting sporadic Parkinson's disease in a Japanese population

\begin{tabular}{|c|c|c|c|c|}
\hline \multirow[b]{3}{*}{ Genotype } & \multicolumn{4}{|c|}{ Caffeine intake } \\
\hline & \multicolumn{2}{|c|}{$\geq 161.7 \mathrm{mg} / 4184 \mathrm{~kJ}$} & \multicolumn{2}{|c|}{$<161.7 \mathrm{mg} / 4184 \mathrm{~kJ}$} \\
\hline & No. cases/controls & Adjusted OR $(95 \% \mathrm{Cl})^{*}$ & No. cases/controls & Adjusted OR $(95 \% \mathrm{Cl})^{*}$ \\
\hline $\mathrm{CC}+\mathrm{CA}$ & $58 / 140$ & 1.00 & $101 / 139$ & $1.82(1.21-2.75)$ \\
\hline AA & $28 / 38$ & $1.87(1.03-3.36)$ & $42 / 40$ & $2.66(1.55-4.59)$ \\
\hline \multicolumn{5}{|c|}{$P$ for multiplicative interaction $=0.55$} \\
\hline \multicolumn{5}{|c|}{ Measures of additive interaction ${ }^{\dagger}$} \\
\hline \multicolumn{5}{|c|}{ Relative excess risk due to interaction (RERI) $=-0.02(95 \% \mathrm{Cl}:-1.63-1.59)$} \\
\hline \multicolumn{5}{|c|}{ Attributable proportion due to interaction (AP) $=-0.01(95 \% \mathrm{Cl}:-0.61-0.60)$} \\
\hline \multicolumn{5}{|c|}{ Synergy index $(S)=0.99(95 \% \mathrm{Cl}: 0.38-2.58)$} \\
\hline
\end{tabular}

*Adjusted for sex, age, region of residence, and smoking.

${ }^{\dagger}$ Statistically significant when the $95 \% \mathrm{Cl}$ of RERI $>0$, the $95 \% \mathrm{Cl}$ of AP $>0$, or the $95 \% \mathrm{Cl}$ of S > 1, indicating additive interaction. 
Table 6 Genotype and allele frequencies from previous case-control studies of Japanese populations investigating the association between UCHL1 S18Y polymorphism and Parkinson's disease*

\begin{tabular}{|c|c|c|c|c|c|c|c|c|}
\hline \multirow[b]{3}{*}{ Genotype } & \multicolumn{2}{|c|}{ Zhang et al. [6] } & \multicolumn{2}{|c|}{ Momose et al. [7] } & \multicolumn{2}{|c|}{ Mizuta et al. [9] $]^{+}$} & \multicolumn{2}{|c|}{ Snapinn et al. [25] } \\
\hline & Cases & Controls & Cases & $\overline{\text { Controls }}$ & Cases & Controls & Cases & Controls \\
\hline & $N=160$ & $N=160$ & $N=230$ & $N=248$ & $N=613$ & $N=736$ & $N=605$ & $N=1620$ \\
\hline$\overline{C C}$ & $52(32.5)$ & $35(21.9)$ & $71(30.9)$ & $61(24.6)$ & $149(24.3)$ & $199(27.0)$ & $150(24.8)$ & $412(25.4)$ \\
\hline CA & $77(48.1)$ & $86(53.8)$ & $119(51.7)$ & $122(49.2)$ & $340(55.5)$ & $366(49.7)$ & $313(51.7)$ & $805(49.7)$ \\
\hline AA & $31(19.4)$ & $39(24.4)$ & $40(17.4)$ & $65(26.2)$ & $124(20.2)$ & $171(23.2)$ & $142(23.5)$ & $403(24.9)$ \\
\hline Allele & $N=320$ & $N=320$ & $N=460$ & $N=496$ & $N=1226$ & $N=1472$ & $N=1210$ & $N=3240$ \\
\hline $\mathrm{C}$ & $181(56.6)$ & $156(48.8)$ & $261(56.7)$ & $244(49.2)$ & $638(52.0)$ & $764(51.9)$ & $613(50.7)$ & $1629(50.3)$ \\
\hline$A$ & $139(43.4)$ & $164(51.3)$ & $199(43.3)$ & $252(50.8)$ & $588(48.0)$ & $708(48.1)$ & $597(49.3)$ & $1611(49.7)$ \\
\hline
\end{tabular}

* $n(\%)$.

${ }^{\dagger}$ Data were based on a meta-analysis by Ragland et al. [5]; excluded cases included in genotype counts in the Momose et al. study [7].

studies with a larger number of subjects and also by functional studies.

\section{Appendix}

Other members of the Fukuoka Kinki Parkinson's Disease Study Group are as follows: Yasuhiko Baba and Tomonori Kobayashi (Department of Neurology, Faculty of Medicine, Fukuoka University); Hideyuki Sawada, Eiji Mizuta, and Nagako Murase (Clinical Research Institute and Department of Neurology, Utano National Hospital); Tsuyoshi Tsutada and Takami Miki (Department of Geriatrics and Neurology, Osaka City University Graduate School of Medicine); Jun-ichi Kira (Department of Neurology, Neurological Institute, Graduate School of Medical Sciences, Kyushu University); Tameko Kihira and Tomoyoshi Kondo (Department of Neurology, Wakayama Medical University); Hidekazu Tomimoto (Department of Neurology, Kyoto University Graduate School of Medicine); Takayuki Taniwaki (Division of Respirology, Neurology, and Rheumatology, Department of Medicine, Kurume University School of Medicine); Hiroshi Sugiyama and Sonoyo Yoshida (Department of Neurology, Minami-Kyoto National Hospital); Harutoshi Fujimura and Tomoko Saito (Department of Neurology, Toneyama National Hospital); Kyoko Saida and Junko Fujitake (Department of Neurology, Kyoto City Hospital); Naoki Fujii (Department of Neurology, Neuro-Muscular Center, National Omuta Hospital); Masatoshi Naito and Jun Arimizu (Department of Orthopaedic Surgery, Faculty of Medicine, Fukuoka University); Takashi Nakagawa, Hirofumi Harada, and Takayuki Sueta (Department of Otorhinolaryngology, Faculty of Medicine, Fukuoka University); Toshihiro Kikuta and George Umemoto (Department of Oral and Maxillofacial Surgery, Faculty of Medicine, Fukuoka University); Eiichi Uchio and Hironori Migita (Department of Ophthalmology, Faculty of Medicine, Fukuoka University); Kenichi Kazuki, Yoichi Ito, and Hiroyoshi Iwaki (Department of Orthopaedic Surgery, Osaka City University Graduate School of Medicine); Kunihiko Siraki and Shinsuke Ataka (Department of Ophthalmology and Visual Sciences, Osaka City University Graduate School of Medicine); Hideo Yamane and Rie Tochino (Department of Otolaryngology and Head and Neck Surgery, Osaka City University Graduate School of Medicine); Teruichi Harada (Department of Plastic and Reconstructive Surgery, Osaka City University Graduate School of Medicine); Yasushi Iwashita, Motoyuki Shimizu, Kenji Seki, and Keiji Ando (Department of Orthopedic Surgery, Utano National Hospital).

\section{Abbreviations}

$A P$, Attributable proportion due to interaction; $\mathrm{Cl}$, Confidence interval; OR, Odds ratio; PD, Parkinson's disease; RERI, Relative excess risk due to interaction; S, Synergy index; UCHL1, Ubiquitin carboxy-terminal hydrolase L1.

\section{Competing interests}

All authors declare that they have no competing interests.

\section{Authors' contributions}

YM contributed to the study design, data collection, overall management, statistical analysis, data interpretation, and writing of the manuscript. KT and WF contributed to the study design, data collection, and data management. SS and CK contributed to the study design. YT, TY, TO, TM, NK, NS and HF contributed to the outcome definition and case recruitment. $\mathrm{YH}$ and $\mathrm{MN}$ contributed to the supervision of the design and execution of the study. Authors listed in the Appendix contributed to case or control subject recruitment. All authors contribute to the preparation of the manuscript and approved the final version submitted for publication.

\section{Acknowledgements}

The authors would like to thank Mrs. Yukari Hayashi for her technical assistance. This study was supported by Health and Labour Sciences Research Grants, Research on Intractable Diseases, Research Committee on Epidemiology of Intractable Diseases from the Ministry of Health, Labour, and Welfare, Japan.

\section{Author details}

'Department of Preventive Medicine and Public Health, Faculty of Medicine, Fukuoka University, Fukuoka, Japan. ${ }^{2}$ Department of Public Health, Osaka City University Graduate School of Medicine, Osaka, Japan. ${ }^{3}$ Department of Preventive Medicine, Graduate School of Medical Sciences, Kyushu University, Fukuoka, Japan. ${ }^{4}$ Department of Social and Preventive Epidemiology, School of Public Health, The University of Tokyo, Tokyo, Japan. ${ }^{5}$ Department of Neurology, Faculty of Medicine, Fukuoka University, Fukuoka, Japan. ${ }^{6}$ Department of Neurology, Clinical Research Institute, Utano National Hospital, Kyoto, Japan. ${ }^{7}$ Department of Geriatrics and Neurology, Osaka City University Graduate School of Medicine, Osaka, Japan. ${ }^{8}$ Department of 
Neurology, Neurological Institute, Graduate School of Medical Sciences, Kyushu University, Fukuoka, Japan. ${ }^{9}$ Human Brain Research Center, Kyoto University Graduate School of Medicine, Kyoto, Japan. ${ }^{10}$ Department of Public Health, Saitama Medical University Faculty of Medicine, Saitama, Japan. ${ }^{11}$ Other members of the Study Group are listed in the Appendix.

Received: 6 March 2012 Accepted: 16 July 2012

Published: 28 July 2012

\section{References}

1. Cook C, Petrucelli L: A critical evaluation of the ubiquitin-proteasome system in Parkinson's disease. Biochim Biophys Acta 2009, 1792:664-675.

2. Wilkinson KD, Lee KM, Deshpande S, Duerksen-Hughes P, Boss JM, Pohl J: The neuron-specific protein PGP 9.5 is a ubiquitin carboxyl-terminal hydrolase. Science 1989, 246:670-673.

3. Larsen CN, Krantz BA, Wilkinson KD: Substrate specificity of deubiquitinating enzymes: ubiquitin C-terminal hydrolases. Biochemistry 1998, 37:3358-3368

4. Cartier AE, Djakovic SN, Salehi A, Wilson SM, Masliah E, Patrick GN: Regulation of synaptic structure by ubiquitin C-terminal hydrolase L1. J Neurosci 2009, 29:7857-7868.

5. Ragland M, Hutter C, Zabetian C, Edwards K: Association between the ubiquitin carboxyl-terminal esterase L1 gene (UCHL1) S18Y variant and Parkinson's Disease: a HuGE review and meta-analysis. Am J Epidemiol 2009, 170:1344-1357.

6. Zhang J, Hattori N, Leroy E, Morris HR, Kubo S, Kobayashi T, Wood NW, Polymeropoulos MH, Mizuno Y: Association between a polymorphism of ubiquitin carboxy-terminal hydrolase L1 (UCH-L1) gene and sporadic Parkinson's disease. Parkinsonism Relat Disord 2000, 6:195-197.

7. Momose Y, Murata M, Kobayashi K, Tachikawa M, Nakabayashi Y, Kanazawa I, Toda T: Association studies of multiple candidate genes for Parkinson's disease using single nucleotide polymorphisms. Ann Neurol 2002, 51:133-136.

8. Wang J, Zhao CY, Si YM, Liu ZL, Chen B, Yu L: ACT and UCH-L1 polymorphisms in Parkinson's disease and age of onset. Mov Disord 2002, 17:767-771

9. Mizuta I, Satake W, Nakabayashi Y, Ito C, Suzuki S, Momose Y, Nagai Y, Oka A, Inoko H, Fukae J, Saito Y, Sawabe M, Murayama S, Yamamoto M, Hattori $\mathrm{N}$, Murata M, Toda T: Multiple candidate gene analysis identifies a-synuclein as a susceptibility gene for sporadic Parkinson's disease. Hum Mol Genet 2006, 15:1151-1158.

10. Tan EK, Puong KY, Fook-Chong S, Chua E, Shen H, Yuen Y, Pavanni R, Wong MC, Puvan K, Zhao Y: Case-control study of UCHL1 S18Y variant in Parkinson's disease. Mov Disord 2006, 21:1765-1768.

11. Maraganore DM, Farrer MJ, Hardy JA, Lincoln SJ, McDonnell SK, Rocca WA: Case-control study of the ubiquitin carboxy-terminal hydrolase L1 gene in Parkinson's disease. Neurology 1999, 53:1858-1860.

12. Wintermeyer $P$, Krüger $R$, Kuhn W, Müller T, Woitalla D, Berg D, Becker $G$ Leroy E, Polymeropoulos M, Berger K, Przuntek H, Schöls L, Epplen JT, Riess $\mathrm{O}$ : Mutation analysis and association studies of the UCHL1 gene in German Parkinson's disease patients. NeuroReport 2000, 11:2079-2082.

13. Mellick GD, Silburn PA: The ubiquitin carboxy-terminal hydrolase-L1 gene S18Y polymorphism does not confer protection against idiopathic Parkinson's disease. Neurosci Lett 2000, 293:127-130.

14. Levecque C, Destée A, Mouroux V, Becquet E, Defebvre L, Amouyel P, Chartier-Harlin MC: No genetic association of the ubiquitin carboxyterminal hydrolase-L1 gene S18Y polymorphism with familial Parkinson's disease. J Neural Transm 2001, 108:979-984.

15. Savettieri G, De Marco EV, Civitelli D, Salemi G, Nicoletti G, Annesi G, Cirò Candiano IC, Quattron A: Lack of association between ubiquitin carboxyterminal hydrolase L1 gene polymorphism and PD. Neurology 2001, 57:560-561

16. Elbaz A, Levecque C, Clavel J, Vidal JS, Richard F, Corrèze JR, Delemotte B, Amouyel P, Alpérovitch A, Chartier-Harlin MC, Tzourio C: S18Y polymorphism in the UCH-L1 gene and Parkinson's disease: evidence for an age-dependent relationship. Mov Disord 2003, 18:130-137.

17. Facheris $\mathrm{M}$, Strain $\mathrm{K}$, Lesnick $T \mathrm{G}$, de Andrade $\mathrm{M}$, Bower $\mathrm{JH}$, Ahlskog JE, Cunningham JM, Lincoln S, Farrer MJ, Rocca WA, Maraganore DM: UCHL1 is associated with Parkinson's disease: a case-unaffected sibling and caseunrelated control study. Neurosci Lett 2005, 381:131-134.
18. Healy DG, Abou-Sleiman PM, Casas JP, Ahmadi KR, Lynch T, Gandhi S, Muqit MM, Foltynie T, Barker R, Bhatia KP, Quinn NP, Lees AJ, Gibson JM, Holton $J \mathrm{~L}$, Revesz T, Goldstein DB, Wood NW: UCHL-1 is not a Parkinson's disease susceptibility gene. Ann Neurol 2006, 59:627-633.

19. Carmine Belin A, Westerlund M, Bergman O, Nissbrandt H, Lind C, Sydow O, Galter D: S18Y in ubiquitin carboxy-terminal hydrolase L1 (UCH-L1) associated with decreased risk of Parkinson's disease in Sweden. Parkinsonism Relat Disord 2007, 13:295-298.

20. Hutter CM, Samii A, Factor SA, Nutt JG, Higgins DS, Bird TD, Griffith A, Roberts JW, Leis BC, Montimurro JS, Kay DM, Edwards KL, Payami H, Zabetian CP: Lack of evidence for an association between UCHL1 S18Y and Parkinson's disease. Eur J Neurol 2008, 15:134-139.

21. Zhang ZJ, Burgunder JM, An XK, Wu Y, Chen WJ, Zhang JH, Wang YC, Xu YM, Gou YR, Yuan GG, Mao XY, Peng R: Lack of evidence for association of a UCH-L1 S18Y polymorphism with Parkinson's disease in a Han-Chinese population. Neurosci Lett 2008, 442:200-202.

22. Wu YR, Chen CM, Chen YC, Chao CY, Ro LS, Fung HC, Hsiao YC, Hu FJ, LeeChen GJ: Ubiquitin specific proteases USP24 and USP40 and ubiquitin thiolesterase UCHL1 polymorphisms have synergic effect on the risk of Parkinson's disease among Taiwanese. Clin Chim Acta 2010, 411:955-958.

23. Wang L, Guo JF, Nie LL, Luo L, Zuo X, Shen L, Jiang H, Yan XX, Xia K, Pan Q, Tang BS: Case-control study of the UCH-L1 S18Y variant in sporadic Parkinson's disease in the Chinese population. J Clin Neurosci 2011, 18:541-544.

24. Tan EK, Lu CS, Peng R, Teo YY, Wu-Chou YH, Chen RS, Weng YH, Chen CM, Fung HC, Tan LC, Zhang ZJ, An XK, Lee-Chen GJ, Lee MC, Fook-Chong S, Burgunder JM, Wu RM, Wu YR: Analysis of the UCHL1 genetic variant in Parkinson's disease among Chinese. Neurobiol Aging 2010, 31:2194-2196.

25. Snapinn KW, Larson EB, Kawakami H, Ujike H, Borenstein AR, Izumi Y, Kaji $R$, Maruyama H, Mata IF, Morino H, Oda M, Tsuang DW, Yearout D, Edwards KL, Zabetian CP: The UCHL1 S18Y polymorphism and Parkinson's disease in a Japanese population. Parkinsonism Relat Disord 2011, 17:473-475.

26. Yasuda T, Nihira T, Ren YR, Cao XQ, Wada K, Setsuie R, Kabuta T, Wada K, Hattori N, Mizuno Y, Mochizuki H: Effects of UCH-L1 on a-synuclein overexpression mouse model of Parkinson's disease. J Neurochem 2009, 108:932-944.

27. Hughes AJ, Daniel SE, Kilford L, Lees AJ: Accuracy of clinical diagnosis of idiopathic Parkinson's disease: a clinico-pathological study of 100 cases. J Neurol Neurosurg Psychiatry 1992, 55:181-184.

28. Miyake Y, Tanaka K, Fukushima W, Kiyohara C, Sasaki S, Tsuboi Y, Yamada T, Oeda T, Shimada H, Kawamura N, Sakae N, Fukuyama H, Hirota Y, Nagai M, Fukuoka Kinki Parkinson's Disease Study Group: SNCA polymorphisms, smoking, and sporadic Parkinson's disease in Japanese. Parkinsonism Relat Disord 2012, 18:557-561.

29. Tanaka K, Miyake Y, Fukushima W, Sasaki S, Kiyohara C, Tsuboi Y, Yamada T, Oeda T, Miki T, Kawamura N, Sakae N, Fukuyama H, Hirota Y, Nagai M, Fukuoka Kinki Parkinson's Disease Study Group: Active and passive smoking and risk of Parkinson's disease. Acta Neurol Scand 2010, 122:377-382.

30. Tanaka K, Miyake Y, Fukushima W, Sasaki S, Kiyohara C, Tsuboi Y, Yamada T, Oeda T, Miki T, Kawamura N, Sakae N, Fukuyama H, Hirota Y, Nagai M, Fukuoka Kinki Parkinson's Disease Study Group: Intake of Japanese and Chinese teas reduces risk of Parkinson's disease. Parkinsonism Relat Disord 2011, 17:446-450.

31. Andersson T, Alfredsson L, Källberg H, Zdravkovic S, Ahlbom A: Calculating measures of biological interaction. Eur J Epidemiol 2005, 20:575-579.

32. Knol MJ, VanderWeele TJ, Groenwold RH, Klungel OH, Rovers MM, Grobbee DE: Estimating measures of interaction on an additive scale for preventive exposures. Eur J Epidemiol 2011, 26:433-438.

33. Lill CM, Roehr JT, McQueen MB, Kavvoura FK, Bagade S, Schjeide BM, Schjeide LM, Meissner E, Zauft U, Allen NC, Liu T, Schilling M, Anderson KJ, Beecham G, Berg D, Biernacka JM, Brice A, DeStefano AL, Do CB, Eriksson N, Factor SA, Farrer MJ, Foroud T, Gasser T, Hamza T, Hardy JA, Heutink P, HillBurns EM, Klein C, Latourelle JC, et al: Comprehensive Research Synopsis and Systematic Meta-Analyses in Parkinson's Disease Genetics: The PDGene Database. PLoS Genet 2012, 8:e1002548.

34. Satake W, Nakabayashi Y, Mizuta I, Hirota Y, Ito C, Kubo M, Kawaguchi T, Tsunoda T, Watanabe M, Takeda A, Tomiyama H, Nakashima K, Hasegawa K, Obata F, Yoshikawa T, Kawakami H, Sakoda S, Yamamoto M, Hattori N, Murata M, Nakamura Y, Toda T: Genome-wide association study identifies common variants at four loci as genetic risk factors for Parkinson's disease. Nat Genet 2009, 41:1303-1307. 
35. Andersson FI, Werrell EF, McMorran L, Crone WJ, Das C, Hsu ST, Jackson SE: The effect of Parkinson's-disease-associated mutations on the deubiquitinating enzyme UCH-L1. J Mol Biol 2011, 407:261-272.

36. Carolan BJ, Heguy A, Harvey BG, Leopold PL, Ferris B, Crystal RG: Upregulation of expression of the ubiquitin carboxyl-terminal hydrolase L1 gene in human airway epithelium of cigarette smokers. Cancer Res 2006, 66:10729-10740.

37. McCulloch CC, Kay DM, Factor SA, Samii A, Nutt JG, Higgins DS, Griffith A, Roberts JW, Leis BC, Montimurro JS, Zabetian CP, Payami H: Exploring gene-environment interactions in Parkinson's disease. Hum Genet 2008, 123:257-265.

doi:10.1186/1471-2377-12-62

Cite this article as: Miyake et al: UCHL1 S18Y variant is a risk factor for

Parkinson's disease in Japan. BMC Neurology 2012 12:62.

\section{Submit your next manuscript to BioMed Central and take full advantage of:}

- Convenient online submission

- Thorough peer review

- No space constraints or color figure charges

- Immediate publication on acceptance

- Inclusion in PubMed, CAS, Scopus and Google Scholar

- Research which is freely available for redistribution 